\title{
Complications and In-Hospital Mortality After On- Pump Vs Off-Pump Coronary Artery Bypass Grafting
}

\author{
Giorgi Janashia; PhD Student \\ Zurab Chkaidze; Full Professor
}

Ivsne Javakhishvili Tbilisi State University, Georgia

Merab Nachkepia; PhD.

Tbilisi Heart And Vascular Clinic, Georgia

\section{Kakha Beselia;}

Aleksandre Aladashvili Clinic Tbilisi, Georgia

Iamze Taboridze, Associate Professor

Grigol Robakidze University, Georgia

Abstract

Off-pump surgery has involved into the most frequently adopted alternative technique to conventional on-pump coronary artery bypass grafting $(\mathrm{CABG})$ in the treatment of patients with coronary artery disease.

Our aim was to compare data analyses of complications and in-hospital mortality after on-pump vs off-pump CABG.

Materials and methods: Retrospective data analyses research is based on 402 patients, ranging in 37-75 years of age. Operations CABG were performed in 2009- 2012, at the West Georgian Interventional Medicine National Center Hospital, Kutaisi; Aleksandre Aladashvili Clinic, Tbilisi; and L.T.D. Lancet, Tbilisi. 253 cases were performed off pump and 149 cases were performed on pump.

Groups were diversified by the F Fischer's criteria. Odds ratio (OR) was made using regression analysis. Statistical analysis was made using SPSS 22 program.

Results: While on pump during surgery, intraoperative shock occurred in $8(5.37 \%)$ cases, Thrombosis $-3(2.01 \%)$; Dissection - 3(2.01\%), Stroke $1(0.67 \%)$ and Myocardial Infarction $-1(0.67 \%)$. These complications were not detected during off pump CABG.

Frequency of in-hospital mortality after off pump and on pump CABG are respectively $7(2.77 \%)$ and $15(10.07 \%)-p<0.0018$. Totally peri operative 
complications were during off pump CABG - 35(13.83\%) and on pump CABG $-41(27.51 \%)(\mathrm{p}<0.0007)$.

In the cases of on pump surgery, odds ratio of complications that arise: bleeding $\quad \mathrm{OR}=4.48(95 \mathrm{CI} ; 1.38-14.54) ; \quad$ atrial fibrillation $\mathrm{OR}=6.64(95 \% \mathrm{CI}: 1.82-24.21)$; pulmonary complications $\mathrm{OR}=2.24(95 \% \mathrm{CI}: 1.19-4.21)$, renal insufficiency - OR=8.75(95\%CI:1.0175.63); in-hospital mortality $-\mathrm{OR}=2.365(95 \% \mathrm{CI}: 1.425-3.924)$.

Conclusion: Off pump CABG seems to significantly reduce postoperative renal failure, bleeding, atrial fibrillation, and respiratory complications, while perioperative myocardial infarction rates remain significantly unchanged. Considering in-hospital mortality and perioperative complications, off pump CABG has much better results.

Keywords: On pump, off pump, complications, hospital mortality

Heart ischemic disease is dominant at invalidation and mortality frequency in population [Allender S, et al., 2007].

During prolonged ischemia, angiography problems, multivessel disease, PCI inability, myocardial surgical revascularization is the most effective method of treatment, it gives opportunity to avoid ischemic symptoms, prolong life expectancy and improve life quality [O'Gara P.T. et al., 2013].

Regarding to surgical strategy, it's been several years that off pump CABG became the appropriate alternative of on pump surgery [Racz M. J. et al., 2004].

Bleeding, low ejection fraction syndrome, postoperative arrhythmias, strokes, these complications are mostly decreased after off pump surgery [Mack M.J. et al., 2002]. Some authors, however, can not find any difference between those two strategies [Møller C.H. et al., 2010].

The aim of our research is to compare on pump and off pump CABG`s data and to assess complications risk.

\section{Materials and methods:}

Retrospective data analyses research is based on 402 patients, ranging in 37-75 years of age. Operations CABG were performed in 2009- 2012, at West Georgian Interventional Medicine National Center Hospital, Kutaisi; Aleksandre Aladashvili Clinic, Tbilisi; and L.T.D. Lancet, Tbilisi. 253 cases were performed off pump and 149 cases were performed on pump. Emergency operations were performed on 149 patients and 308 patients were planed procedures. Within each group, postoperative outcomes were compared according to whether patients underwent off-pump or on-pump coronary bypass surgery. Outcome was in-hospital mortality, postoperative stroke, renal 
failure, MI, heart failure, bleeding, intraoperative shock, thrombosis, dissection.

\section{Inclusion criteria}

Patients who were operated on for one or multiple coronary artery diseases. Patients informed agreement about taking part in medical research.

\section{Exclusion criteria}

Terminal stage of heart, renal or pulmonary chronic diseases.

Examination methods: anamnesis, E.C.G., echocardiography, coronary angiography, clinical laboratory tests, biochemistry.

\section{Statistical analysis}

Data was processed by variation statistical method. Average and standard deviation were studied. Groups were diversified by the F Fischer's criteria. Odds ratio (OR) was made using regression analysis. Statistical analysis was made using SPSS 22 program.

\section{Results}

Baseline characteristics of patients by the age, gender and Comorbidities is shown in Table 1.

Table 1.

Baseline characteristics of patients

\begin{tabular}{|c|c|c|c|c|c|c|c|}
\hline & & \multicolumn{2}{|c|}{$\begin{array}{c}\text { off pump } \\
{[n=253]}\end{array}$} & \multicolumn{2}{|c|}{$\begin{array}{c}\text { on pump } \\
{[n=149]}\end{array}$} & \multirow[t]{2}{*}{$\mathrm{F}$} & \multirow{2}{*}{$\mathrm{p}$} \\
\hline & & abs & $\%$ & abs & $\%$ & & \\
\hline \multirow{4}{*}{ Age } & $<45$ & 14 & 55.34 & 13 & 8.73 & 1.52 & 0.2180 \\
\hline & $45-60$ & 86 & 33.99 & 63 & 42.28 & 2.77 & 0.0970 \\
\hline & $61-75$ & 136 & 53.76 & 66 & 44.30 & 3.37 & 0.0672 \\
\hline & $>75$ & 17 & 6.72 & 7 & 4.70 & 0.68 & 0.4100 \\
\hline Sex & Female & 59 & 23.32 & 34 & 22.82 & 0.01 & 0.9086 \\
\hline \multirow{5}{*}{$\begin{array}{c}\text { Co- } \\
\text { morbidities }\end{array}$} & $\begin{array}{l}\text { Diabetes } \\
\text { Mellitus }\end{array}$ & 73 & 28.85 & 32 & 21.48 & 2.65 & 0.1044 \\
\hline & Obesity & 18 & 7.11 & 13 & 8.72 & 0.34 & 0.5600 \\
\hline & Hypertension & 226 & 89.33 & 103 & 69.13 & 27.37 & 0.0000 \\
\hline & Renal failure & 2 & 0.79 & 1 & 0.67 & 0.02 & 0.8935 \\
\hline & COPD & 2 & 0.79 & 1 & 0.67 & 0.02 & 0.8935 \\
\hline
\end{tabular}

As it has been shown starting data of both groups is nearly the same. Patients with age range 61-75 prevail in both groups. Hypertension is higher in off pump group.

Perioperative complications were studied in both groups (Table 2). 
Table 2 Accessing complications frequency statistics by operation techniques

\begin{tabular}{|c|c|c|c|c|c|c|}
\hline & \multicolumn{2}{|c|}{$\begin{array}{c}\text { off pump } \\
{[\mathrm{n}=253]}\end{array}$} & \multicolumn{2}{c|}{$\begin{array}{c}\text { on pump } \\
\text { [n=149] }\end{array}$} & \multirow{2}{*}{$\mathrm{F}$} & $\mathrm{P}$ \\
\hline & $\mathrm{abs}$ & $\%$ & $\mathrm{abs}$ & $\%$ & & \\
\hline Intraoperative shock & 0 & 0.00 & 8 & 5.37 & 14.28 & 0.0002 \\
\hline Thrombosis & 0 & 0.00 & 3 & 2.01 & 5.17 & 0.0235 \\
\hline Myocardial Infarction & 0 & 0.00 & 1 & 0.67 & 1.70 & 0.1929 \\
\hline Bleeding & 4 & 1.58 & 10 & 6.71 & 7.44 & 0.0067 \\
\hline Heart failure & 11 & 4.35 & 8 & 5.37 & 0.22 & 0.6422 \\
\hline Dissection & 0 & 0.00 & 3 & 2.01 & 5.17 & 0.0235 \\
\hline Atrial fibrillation & 3 & 1.19 & 11 & 7.38 & 10.95 & 0.0010 \\
\hline Pneumonia & 17 & 6.72 & 8 & 5.37 & 0.29 & 0.5893 \\
\hline Plevritis & 2 & 0.79 & 2 & 1.34 & 0.29 & 0.5914 \\
\hline Stroke & 0 & 0.00 & 1 & 0.67 & 1.70 & 0.1929 \\
\hline Pulmonary complications & 20 & 7.91 & 24 & 16.11 & 6.55 & 0.0109 \\
\hline Acute renal failure & 1 & 0.40 & 5 & 3.36 & 5.64 & 0.0180 \\
\hline
\end{tabular}

In case of off pump surgery there were no such complications like: intraoperative shock, thrombosis, myocardial Infarction, dissections, stroke. Mean while those complications are met at on pump 2-5\% cases. Besides in case of on pump surgery frequency of bleeding, acute renal failure, atrial fibrillation, pulmonary complications are much higher.

Frequency of total perioperative complications and in-hospital mortality by operation techniques are shown in Figure 1, Factor "total complication" was at list one of the complications we examined.

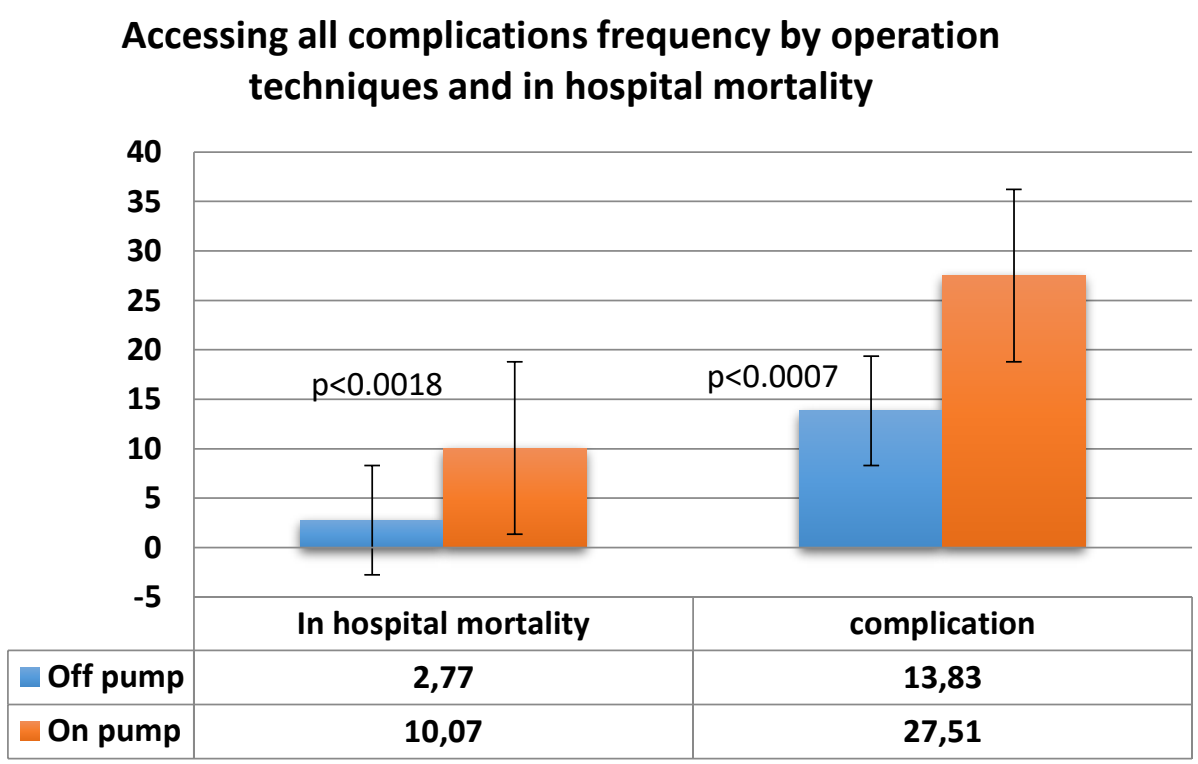

Figure 1 
As it has been shown: total in-hospital complications and in-hospital mortality are significantly higher in the cases of on pump surgery.

With statistical analysis conducted, opportunity was gained to determine odds ratio perioperative complications and mortality risk, depending on surgery methods (Table 3).

Table 3 Determination of perioperative complications and mortality risk, depending on surgery methods: on pump CABG vs. off pump CABG.

\begin{tabular}{|c|c|c|}
\hline & OR & $95 \%$ CI \\
\hline Bleeding & 4.48 & $1.38-14.54$ \\
\hline Heart failure & 1.25 & $0.49-3.18$ \\
\hline atrial fibrillation & 6.64 & $1.82-24.21$ \\
\hline Pneumonia & 0.79 & $0.33-1.87$ \\
\hline Plevritis & 1.71 & $0.24-12.25$ \\
\hline Pulmonary complications & 2.24 & $1.19-4.21$ \\
\hline Renal insufficiency & 8.75 & $1.01-75.63$ \\
\hline In-hospital mortality & 3.93 & $1.57-9.89$ \\
\hline Total complications & 2.37 & $1.43-3.92$ \\
\hline
\end{tabular}

Our study has shown that risk of bleeding, fibrillation, renal insufficiency, pulmonary and all complications, hospital mortality are much higher when using on pump $\mathrm{CABG}$ compared to off pump CABG.

\section{Discussion}

During last 50 years coronary artery bypass grafting has become golden standard of multivessel coronary disease in those patients where PCI is not feasible [Goy JJ. et al., 2008, Tatoulis J. et al., 2004].

Off-pump surgery has evolved into the most frequently adopted alternative technique to conventional on-pump coronary artery bypass grafting $(\mathrm{CABG})$ in the treatment of patients with coronary artery disease (CAD) over the last two decades [Davierwala, P. M. 2016].

But the methods of CABG are still to negotiate, should we choose off pump or on pump method. Optimal strategy is yet to discuss, according to some researches, both methods are affordable and safe [Samim D. et al., 2010]. Off pump surgery strategy allows to reduction of bleeding, low ejection fraction syndrome, post operative arrhythmia, neurological complications[Mack M.J.2002]. Our study has shown during on pump surgery thrombosis are in 3(2.01\%) cases, Dissection - 3(2.01\%), stroke $1(0.67 \%)$ and Myocardial Infarction $-1(0.67 \%)$. These complications were not detected during off pump CABG.

Neurological complications are one of the frequent complications of coronary artery surgery. Stroke and coma mortality are impacting at the success and price of procedure [Brown PP. et al., 2008].

According to several meta-analysis, postoperative risk of stroke are high on CABG than OPCAB [Altarabsheh SE et al., 2015; Wang et al., J, 
2015] and it is 2-3\%, using OPCAB risk is dominated [ Emmert MY. et al., 2013].

According to our data during OPCAB there was no intra operative shock or stroke, it was respectively $5.37 \%$ and $0.67 \%$ in cases. These complications were not detected at the time of CABG pump.

The most influential independent factor of mortality is renal insufficiency, [Chertow GM. et al., 1998] it is one of the common complications in cardiac surgery, which impacts outcome. According to data, $30 \%$ of patients are complicated with renal insufficiency [Haase $\mathrm{M}$ et al., 2007; Rosner et al., 2006]. In our data, renal insufficiency is much higher in CABG group, and CPB is hardly impacting renal function.

According to literature: Some secondary end points, including rates of bleeding, acute kidney injury, and respiratory complications, favored offpump CABG. [Lamy A, et al., 2012]. According to our data - CABG comparing to OPCAB complications: bleeding, pulmonary problems,renal insufficiency, fibrillations and hospital mortality are much higher. Moller et al. has discussed 30 day result in high risk patients. Risks were: heart arrest, successful reanimation, infraction, cardiogenic shock, stroke, coronary reintervention. Comparing with those criteria's there were no difference between two methods (15\% VS17\%; P=0.48) [Møller $\mathrm{CH}$. et al., 2010]. Frequency of in-hospital mortality after off pump and on pump CABG are $7(2.77 \%)$ and $15(10.07 \%)-\mathrm{p}<0.0018$ respectively. Total perioperative complications during off pump $\mathrm{CABG}-35(13.83 \%)$ and on pump CABG 41(27.51\% $)(\mathrm{p}<0.0007)$.

Excessive bleeding may be related to a coagulopathy resulting from greater heparin doses during CPB as guided by dosing protocols based on body weight and activated coagulation time (ACT) values or with maintenance of a defined heparin concentration [Raja, S. G., \& Dreyfus, G. D. 2006]. In cases of on pump surgery, increase risk of bleeding $\mathrm{OR}=4.48(95 \mathrm{CI} ; 1.38-14.54)$. In cases of on pump surgery odds ratio of complications arising: atrial fibrillation - $\quad \mathrm{OR}=6.64(95 \% \mathrm{CI}: 1.82-24.21)$; pulmonary complications $\mathrm{OR}=2.24(95 \% \mathrm{CI}: 1.19-4.21)$, renal insufficiency- OR=8.75(95\%CI:1.0175.63); in-hospital mortality $-\mathrm{OR}=2.365(95 \% \mathrm{CI}: 1.425-3.924)$.

In our case we found that $\mathrm{CPB}$ is rising odds ratio of negative perioperative outcome.

\section{Conclusion}

Off pump CABG compared to on pump CABG significantly reduce postoperative renal failure, bleeding, myocardial fibrillation, and pulmonary complications. While perioperative atrial infarction, Pneumonia, Plevritis and Heart failure rates remain significantly unchanged. 
Considering in-hospital mortality and perioperative complications, off pump CABG produced better results.

\section{References:}

1. Allender, S., Peto, V., Scarborough, P., Boxer, A., \& Rayner, M. (2007). Coronary heart disease statistics.

2. Altarabsheh, S. E., Deo, S. V., Rababa'h, A. M., Lim, J. Y., Cho, Y. H., Sharma, V., ... \& Park, S. J. (2015). Off-pump coronary artery bypass reduces early stroke in octogenarians: a meta-analysis of 18,000 patients. The Annals of thoracic surgery, 99(5), 1568-1575.

3. Brown, P. P., Kugelmass, A. D., Cohen, D. J., Reynolds, M. R., Culler, S. D., Dee, A. D., \& Simon, A. W. (2008). The frequency and cost of complications associated with coronary artery bypass grafting surgery: results from the United States Medicare program. The Annals of thoracic surgery, 85(6), 1980-1986.

4. Chertow, G. M., Levy, E. M., Hammermeister, K. E., Grover, F., \& Daley, J. (1998). Independent Association between Acute Renal Failure and Mortality following Cardiac Surgery 12. The American journal of medicine, 104(4), 343-348.

5. Davierwala, P. M. (2016). Current outcomes of off-pump coronary artery bypass grafting: evidence from real world practice. Journal of Thoracic Disease, 8(Suppl 10), S772-S786.

6. Emmert, M. Y., Seifert, B., Wilhelm, M., Grünenfelder, J., Falk, V., \& Salzberg, S. P. (2011). Aortic no-touch technique makes the difference in off-pump coronary artery bypass grafting. The Journal of Thoracic and Cardiovascular Surgery, 142(6), 1499-1506.

7. Goy, J. J., Kaufmann, U., Hurni, M., Cook, S., Versaci, F., Ruchat, P., ... \& Eeckhout, E. (2008). 10-year follow-up of a prospective randomized trial comparing bare-metal stenting with internal mammary artery grafting for proximal, isolated de novo left anterior coronary artery stenosis: the SIMA (Stenting Versus Internal Mammary Artery Grafting) trial. Journal of the American College of Cardiology, 52(10), 815-817.

8. Haase, M., Haase-Fielitz, A., Bagshaw, S. M., Ronco, C., \& Bellomo, R. (2007). Cardiopulmonary bypass-associated acute kidney injury: a pigment nephropathy?. In Acute Kidney Injury (Vol. 156, pp. 340353). Karger Publishers.

9. Lamy, A., Devereaux, P. J., Prabhakaran, D., Taggart, D. P., Hu, S., Paolasso, E., ... \& Noiseux, N. (2012). Off-pump or on-pump coronary-artery bypass grafting at 30 days. New England Journal of Medicine, 366(16), 1489-1497. 
10. Mack, M., Bachand, D., Acuff, T., Edgerton, J., Prince, S., Dewey, T., \& Magee, M. (2002). Improved outcomes in coronary artery bypass grafting with beating-heart techniques. The Journal of thoracic and cardiovascular surgery, 124(3), 598-607.

11. Møller, C. H., Perko, M. J., Lund, J. T., Andersen, L. W., Kelbæk, H., Madsen, J. K., ... \& Steinbrüchel, D. A. (2010). No major differences in 30-day outcomes in high-risk patients randomized to off-pump versus on-pump coronary bypass surgery: the best bypass surgery trial. Circulation, 121(4), 498-504.

12. O'Gara, P. T., Kushner, F. G., Ascheim, D. D., Casey, D. E., Chung, M. K., De Lemos, J. A., ... \& Granger, C. B. (2013). 2013 ACCF/AHA guideline for the management of ST-elevation myocardial infarction: a report of the American College of Cardiology Foundation/American Heart Association Task Force on Practice Guidelines. Journal of the American College of Cardiology, 61(4), e78-e140.

13. Racz, M. J., Hannan, E. L., Isom, O. W., Subramanian, V. A., Jones, R. H., Gold, J. P., ... \& Lancey, R. A. (2004). A comparison of shortand long-term outcomes after off-pump and on-pump coronary artery bypass graft surgery with sternotomy. Journal of the American College of Cardiology, 43(4), 557-564.

14. Raja, S. G., \& Dreyfus, G. D. (2006). Impact of Off-Pump Coronary Artery Bypass Surgery on Postoperative Bleeding: Current Best Available Evidence. Journal of cardiac surgery, 21(1), 35-41.

15. Rosner, M. H., \& Okusa, M. D. (2006). Acute kidney injury associated with cardiac surgery. Clinical journal of the American Society of Nephrology, 1(1), 19-32.

16. Samim, D., Tozzi, P., \& Ferrari, E. (2015). Surgical outcome after isolated on-pump and off-pump anterior descending coronary revascularisation. Swiss Med Wkly, 28(145), w14239.

17. Tatoulis, J., Buxton, B. F., \& Fuller, J. A. (2004). Patencies of 2,127 arterial to coronary conduits over 15 years. The Annals of thoracic surgery, 77(1), 93-101.

18. Wang, J., Gu, C., Gao, M., Yu, W., Li, H., Zhang, F., \& Yu, Y. (2015). Comparison of the incidence of postoperative neurologic complications after on-pump versus off-pump coronary artery bypass grafting in high-risk patients: A meta-analysis of 11 studies. International journal of cardiology, 185, 195-197. 